\title{
Growth of White Matter in the Adolescent Brain: Role of Testosterone and Androgen Receptor
}

\author{
Jennifer S. Perrin, ${ }^{1}$ Pierre-Yves Hervé, ${ }^{1}$ Gabriel Leonard, ${ }^{2}$ Michel Perron, ${ }^{4}$ G. Bruce Pike, ${ }^{2}$ Alain Pitiot, ${ }^{1}$ Louis Richer,${ }^{5}$ \\ Suzanne Veillette, ${ }^{4}$ Zdenka Pausova, ${ }^{1,3}$ and Tomáš Paus ${ }^{1,2}$ \\ ${ }^{1}$ Brain and Body Centre, University of Nottingham, Nottingham NG7 2RD, United Kingdom, ${ }^{2}$ Montreal Neurological Institute, McGill University, Montreal, \\ Quebec, Canada H3A 2B4, ${ }^{3}$ Centre de recherche, Centre hospitalier de l'Université de Montreal, Montreal, Quebec, Canada H2L 4M1, ${ }^{4} L e$ Groupe d'étude \\ des conditions de vie et des besoins de la population (ÉCOBES), Collège d'enseignement général et professionnel (CÉGEP) Jonquiere, Jonquiere, Quebec, \\ Canada G7X 3W1, and 5Department of Psychology, University of Quebec in Chicoutimi, Chicoutimi, Quebec, Canada
}

The growth of white matter during human adolescence shows a striking sexual dimorphism; the volume of white matter increases with age slightly in girls and steeply in boys. Here, we provide evidence supporting the role of androgen receptor (AR) in mediating the effect of testosterone on white matter. In a large sample of typically developing adolescents ( $n=408,204$ males), we used magnetic resonance imaging and acquired T1-weighted and magnetization transfer ratio (MTR) images. We also measured plasma levels of testosterone and genotyped a functional polymorphism in the AR gene, namely the number of CAG repeats in exon 1 believed to be inversely proportional to the AR transcriptional activity. We found that the testosterone-related increase of white-matter volume was stronger in male adolescents with the lower versus higher number of CAG repeats in the AR gene, with testosterone explaining, respectively, 26 and $8 \%$ of variance in the volume. The MTR results suggest that this growth is not related to myelination; the MTR decreased with age in male adolescents. We speculate that testosterone affects axonal caliber rather than the thickness of the myelin sheath.

Key words: adolescence; brain; MRI; myelination; depression; axonal caliber

\section{Introduction}

White matter of a 20 -year-old man contains a staggering $176,000 \mathrm{~km}$ of myelinated axons (Marner et al., 2003). Axons ensure smooth communication throughout the brain in two important ways: by conducting electrical impulses and by transporting various molecules and organelles from the cell body to the synapse (Barry et al., 2007). Hence, the importance of maturational changes in white matter (WM) during childhood and adolescence for the child's cognitive development and mental health.

The growth of WM during childhood and adolescence follows a strikingly different trajectory in girls and boys; it increases with age slightly in girls and steeply in boys (De Bellis et al., 2001; Lenroot et al., 2007). This sexual dimorphism remains unexplained, however. An as-yet-untested assumption is that the agerelated increase in WM during male adolescence is mediated by

Received March 20, 2008; revised Aug. 12, 2008; accepted Aug. 19, 2008.

This work was supported by the Canadian Institutes of Health Research, Heart and Stroke Foundation of Quebec, and the Canadian Foundation for Innovation. P.-Y.H. is supported by a grant from the Fondation Recherche Medicale. We thank the following individuals for their contributions in designing the protocol and acquiring and analyzing the data: Dr. Michel Bérubé, Sylvie Masson, Suzanne Castonguay, Julien Grandisson, and Marie-Josée Morin (MR team); Chantale Belleau, Mélanie Drolet, Catherine Harvey, Stéphane Jean, Hélène Simard, Mélanie Tremblay, and Patrick Vachon (psychometricians); Nadine Arbour, Julie Auclair, Marie-Ėve Blackburn, Marie-Ėve Bouchard, Annie Houde, Catherine Lavoie, and Dr. Luc Laberge (ÉCOBES team), and Julie Bérubé. We thank Dr. Jean Mathieu for the medical follow-up of subjects in whom we detected any medically relevant abnormalities.

Correspondence should be addressed to Prof. Tomáš Paus, Brain and Body Centre, University of Nottingham, University Park, Nottingham NG7 2RD, UK. E-mail: tomas.paus@nottingham.ac.uk.

DOI:10.1523/JNEUROSCI.1212-08.2008

Copyright $\odot 2008$ Society for Neuroscience $\quad 0270-6474 / 08 / 289519-06 \$ 15.00 / 0$ the effect of testosterone on myelination. We tested this hypothesis by acquiring structural magnetic resonance (MR) images in a large cohort of adolescents together with measuring testosterone levels in blood and evaluating a common functional polymorphism in the androgen receptor (AR) gene.

To evaluate the role of the AR receptor in mediating the effect of testosterone on white matter, we chose the known functional polymorphism in the AR gene that is determined by a variable number of CAG repeats in exon 1 of the gene; this segment encodes a polyglutamine stretch of variable length in the receptor protein (Zitzmann, 2007). The number of CAG repeats is inversely related to the transcriptional activity of androgendependent genes (Hsiao et al., 1999; Irvine et al., 2000). Pathologically high number of CAG repeats is present in individuals with X-linked spinal and bulbar muscular atrophy (Kennedy disease) who also show signs of hypogonadism (La Spada et al., 1991).

Whether or not age-related changes in white-matter volume during male adolescence are related to myelination is unknown. Unfortunately, there is no MR technique that would allow one to measure directly myelin content in vivo. Several indirect approaches have been proposed, including the measurement of magnetization transfer ratio (MTR) and T2 relaxation times (Laule et al., 2007). Given the large-scale nature of our study, we have chosen the measurement of MTR throughout the brain as an indirect index of myelination. It is well established that MTR provides information on the macromolecular content and structure of the tissue (McGowan, 
Table 1. Demographics of the participants split both by sex and the variant of the AR gene

\begin{tabular}{|c|c|c|c|c|c|}
\hline & $n$ & Age (months) & Tanner stage & Bioavailable testosterone $(\mathrm{nmol} / \mathrm{l})$ & Full-scale IQ \\
\hline Females & 204 & $183.88(23.54)$ & $4.16(0.71)$ & & 104.93 (11.84) \\
\hline Males & 204 & $180.60(22.39)$ & $3.47(0.89)$ & & $105.22(12.85)$ \\
\hline Short AR gene & 99 & $182.62(22.47)$ & $3.55(0.89)$ & $8.8 \pm 5.3$ & $106.28(13.34)$ \\
\hline Long AR gene & 85 & $180.51(22.97)$ & $3.45(0.88)$ & $9.3 \pm 5.6$ & $104.84(12.63)$ \\
\hline
\end{tabular}

For the analyses of MTR, there were 147 females and 140 males (short AR gene, $n=69$; long AR gene, $n=63$ ). The mean (SD) is shown.

1999); the macromolecules of myelin are the dominant source of MT signal in white matter (Kucharczyk et al., 1994). This interpretation of MTR is further supported by postmortem data that revealed a significant positive correlation between myelin content and MTR (Schmierer et al., 2004, 2008). Nonetheless, it should be pointed out that MTR is not absolutely specific to myelin and that differences in MTR values can arise, especially under pathological conditions, from a number of other sources including water content or astrocytic swelling (Laule et al., 2007; Rovira et al., 2001).

We used the above MR approaches, together with the assessment of plasma levels of testosterone, the AR genotype, and psychopathology, in a large-scale study of adolescence (Pausova et al., 2007). Our results suggest that a genetic variation in the AR gene moderates the effect of testosterone on WM volume during male adolescence and that the age-related increases in the volume cannot be explained by increases in myelination.

\section{Materials and Methods}

Subjects. All participants of this cross-sectional study were French Canadians recruited from a geographically isolated population of French Canadian origin living in the Saguenay Lac Saint-Jean (SLSJ) region of Quebec, Canada. At the time of analysis, 408 adolescents between 12 and 18 years of age had completed the study protocol. Table 1 provides details concerning the participants, including their age, stage of pubertal development, plasma levels of bioavailable testosterone, and full-scale intelligence quotient (IQ). Details of the recruitment and testing procedures are provided by Pausova et al. (2007). Briefly, subjects were recruited in secondary schools in the SLSJ region. A research nurse conducted a telephone interview with interested families (usually with the child's mother) to verify their eligibility. Additional information was acquired using a medical questionnaire completed by the child's biological parent. The main exclusion criteria were as follows: (1) positive history of alcohol abuse during pregnancy; (2) positive medical history for meningitis, malignancy, and heart disease requiring heart surgery; (3) severe mental illness (e.g., autism, schizophrenia) or mental retardation (IQ $<70$ ); and (4) MR contraindications.

Puberty Development Scale and serum testosterone. All participants filled out the Puberty Development Scale (PDS) (Peterson et al., 1988), which is an eight-item self-report measure of physical development based on the Tanner stages with separate forms for males and females. For this scale, there are five categories of pubertal status: (1) prepubertal, (2) beginning pubertal, (3) midpubertal, (4) advanced pubertal, and (5) postpubertal. Participants answer questions about their growth in stature and pubic hair, as well as menarche in females and voice changes in males. Dorn et al. (1990) compared self-ratings and physician ratings of pubertal development and found significant correlations between adolescent self-rating and physician's rating. In our sample, levels of bioavailable testosterone correlated with selfrated pubertal stage in boys $(r=0.604 ; p<0.0001)$. Therefore, the self-rated PDS likely provides a valid measure of pubertal development.

Fasting blood samples were taken in the morning (between 8:00 and 9:00 A.M.) and analyzed via radioimmunoassay (Testosterone RIA DSL4000; Diagnostic Systems Laboratory) to measure serum levels of testos- terone (nanomoles per liter) and sex-hormone-binding globulin. The level of bioavailable testosterone (nanomoles per liter) was then calculated using an equation developed by Södergård et al. (1982).

Assessment of general intelligence and psychopathology. We used the Wechsler Intelligence Scale for Children (WISC-III) to assess general intelligence. This assessment was performed at the beginning of a $6 \mathrm{~h}$ neuropsychological battery.

In addition, we used the Diagnostic Interview Schedule for Children (DISC) Predictive Scales (DPSs) (Lucas et al., 2001) to evaluate the likelihood of psychiatric diagnosis. This is a self-report questionnaire answered by the adolescent; it contains a total of 98 questions about possible symptoms of psychiatric disorders. In the case of depression, for example, seven questions are asked including "was there a time when you had less energy than normal?" and "was there a time when you seriously thought about killing yourself?" To establish an epidemiological diagnosis of disorders listed in supplemental Table 1 (available at www. jneurosci.org as supplemental material), we used the full-scale cutoff criteria established by Lucas et al. (2001); using these criteria, Lucas et al. (2001) found an excellent agreement between the DPS-based diagnosis and a diagnosis based on the full DISC.

$M R$ image acquisition and analysis. For each participant, highresolution MR images of the brain were acquired on a Phillips 1.0-T superconducting magnet. T1-weighted images were acquired using the following parameters: three-dimensional (3D) radio frequency (RF)spoiled gradient-echo scan with 140-160 slices, an isotropic resolution of $1 \mathrm{~mm}$, a repetition time (TR) of $25 \mathrm{~ms}$, an echo time (TE) of $5 \mathrm{~ms}$, and flip angle of $30^{\circ}$.

Magnetization transfer images were acquired using a dual acquisition (3D RF-spoiled gradient-echo scan with $\sim 50$ slices of $3 \mathrm{~mm}$ thickness and $1 \mathrm{~mm}$ in-plane resolution; TR, $41 \mathrm{~ms}$; TE, $7.9 \mathrm{~ms}$; flip angle, $20^{\circ}$ ) with and without an MT saturation pulse (Gaussian RF pulse of $7.68 \mathrm{~ms}$ duration, $1.5 \mathrm{kHz}$ off resonance, and $500^{\circ}$ effective pulse angle).

Computational analysis of the MR images was used to calculate the volume of WM in male and female adolescents. Volumes of WM in the frontal, parietal, temporal, and occipital lobes were generated using an automated process involving nonlinear registration to a template brain and tissue classification (for details, see Paus, 2005). To correct for interindividual differences in brain size, we calculated relative volumes of WM by dividing the absolute lobar volumes by the total brain volume. In the rest of the study, "volumes of WM" refer to these relative volumes.

MTR images were calculated as the percentage of signal change between the two acquisitions (Pike, 1996). The mean MTR values for WM tissue were calculated, in native space, across all WM voxels constituting a given lobar mask of WM in that subject. For technical reasons, the MTR images of the first 90 subjects (acquired between November 15, 2003, and September 25, 2004) had to be discarded and were therefore not included in any of the analyses. Subjects with and without MTR did not differ significantly in sex composition, age, pubertal stage, and full-scale IQ.

Genotyping of the androgen receptor gene. PCRs were performed using $100 \mathrm{ng}$ of genomic DNA in a total volume of $8.0 \mu \mathrm{l}$ containing $1.0 \mathrm{mM} \mathrm{MgCl}_{2}$ (Qiagen), $1 \times$ PCR buffer containing $1.5 \mathrm{~mm} \mathrm{MgCl}_{2}$ (Qiagen), $0.035 \mu \mathrm{M}$ dNTPs (Qiagen), $0.04 \mathrm{U} / \mu \mathrm{l}$ HotstarTaq DNA polymerase (Qiagen), and $200 \mathrm{~nm}$ forward and reverse primer. PCR protocol was initiated by denaturing the samples at $95^{\circ} \mathrm{C}$ for $10 \mathrm{~min}$ followed by 45 cycles containing a denaturation phase at $95^{\circ} \mathrm{C}$ for $30 \mathrm{~s}$, 
an annealing phase at $60^{\circ} \mathrm{C}$ for $30 \mathrm{~s}$, and an extension phase at $72^{\circ} \mathrm{C}$ for $30 \mathrm{~s}$. The final extension was done at $72^{\circ} \mathrm{C}$ for $7 \mathrm{~min}$. A reading mixture was prepared with $2 \mu \mathrm{l}$ of PCR products, $0.15 \mu \mathrm{l}$ of Genescan $500 \mathrm{Liz}$ size standard (Applied Biosystems), and $8.5 \mu \mathrm{l}$ of Hi-Di Formamide (Applied Biosystems) and migrated on Applied Biosystems 3730xl DNA Analyzer. The genotypes were analyzed with the Applied Biosystems GeneMapper analysis program (release 3.7, October 12, 2004). In our sample of male adolescents, the number of CAG repeats varied between 8 and 32, with a median of 21.7 repeats. Based on the median split, we divided the adolescents into those with a "short" ( $\leq 22$ CAG repeats) and a "long" ( $\geq 23$ CAG repeats) AR gene.

Statistics. We analyzed the data using linear regression models, with the relative volume of WM and MTR as dependent variables. To consider independent effects of age and levels of bioavailable testosterone, we calculated semipartial correlation coefficients. These differ from partial correlations in that the relationships between independent variables are accounted for but the dependent variable remains unchanged (Howell, 1997). The squared semipartial correlation coefficient indicates the proportion of variance explained specifically by either age or testosterone. It excludes, however, the proportion of variance that is explained by the variance that is shared between the two independent variables. In our case, the proportion attributed to the shared variance can be calculated by subtracting the sum of the independent contributions of age and bioavailable testosterone $\left(r_{\mathrm{sp}}{ }^{2}\right)$ from the total amount of variance explained by the model $\left(R^{2}\right)$.

\section{Results}

Figure $1 A$ and Table 2 provide confirmation of the striking sexual dimorphism in age-related increases in relative (i.e., corrected for the total brain volume) volume of WM during adolescence. Age explained 23 and 3\% of variance in WM volume in males and females, respectively.

In male adolescents, significant relationships were observed between bioavailable testosterone and WM volume $\left(r^{2}=0.16\right.$; $p<0.0001)$ but also, as expected, between bioavailable testosterone and age $\left(r^{2}=0.42 ; p<0.0001\right)$. The amount of variance explained by bioavailable testosterone above and beyond age was low $(1 \% ; p=0.082)$. The known functional polymorphism in the AR gene was used as an alternative strategy for evaluating the effect of testosterone on WM.

Figure $1 B$ and Table 3 reveal the moderating effect of AR genotype on the relationship between testosterone and WM volume in adolescent males with low ( $\leq 22$; short AR; $n=97$ ) and high ( $\geq 23$; long AR; $n=82$ ) numbers of CAG repeats. Levels of bioavailable testosterone predicted 26 and $8 \%$ of variance in WM volume in male adolescents with short and long AR genes, respectively. The difference between the two groups in this relationship approached statistical significance in the entire group ( $p=0.08$; two tailed) and was significant $(p=0.03)$ when evaluated in the subset of male adolescents with the available MTR values. Note that male adolescents with the different AR genes did not differ in the pubertal stage or the mean plasma levels of bioavailable testosterone (Table 1).

Table 2 reveals the effect of age on MTR values, an indirect index of myelination. Age explained 8 and 1\% variance in MTR values in male and female adolescents, respectively. The MTR values decreased with increasing age in male adolescents.

Figure $1 C$ and Table 3 reveal the moderating effect of AR genotype on the relationship between testosterone and MTR values in white matter in adolescent males. Levels of bioavailable testosterone predicted 27 and $8 \%$ of variance in MTR values in adolescents with short and long AR genes, respectively.

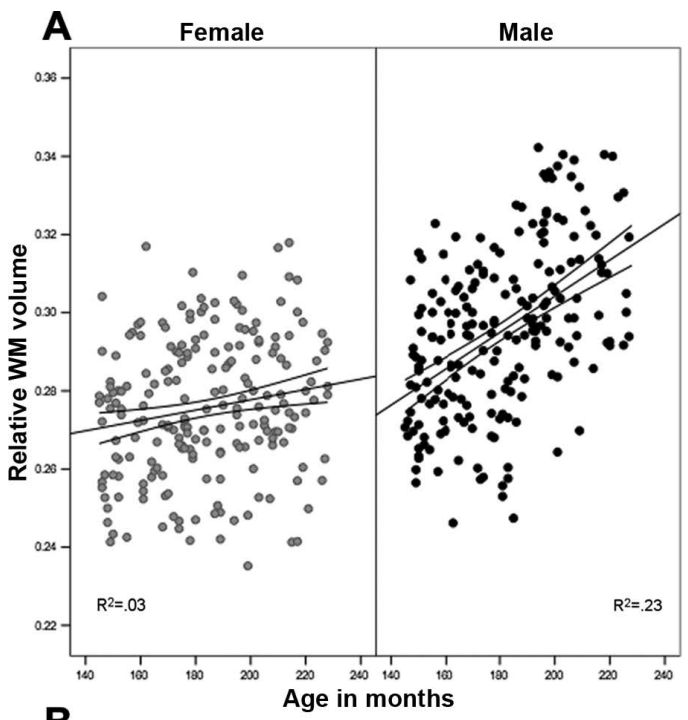

B
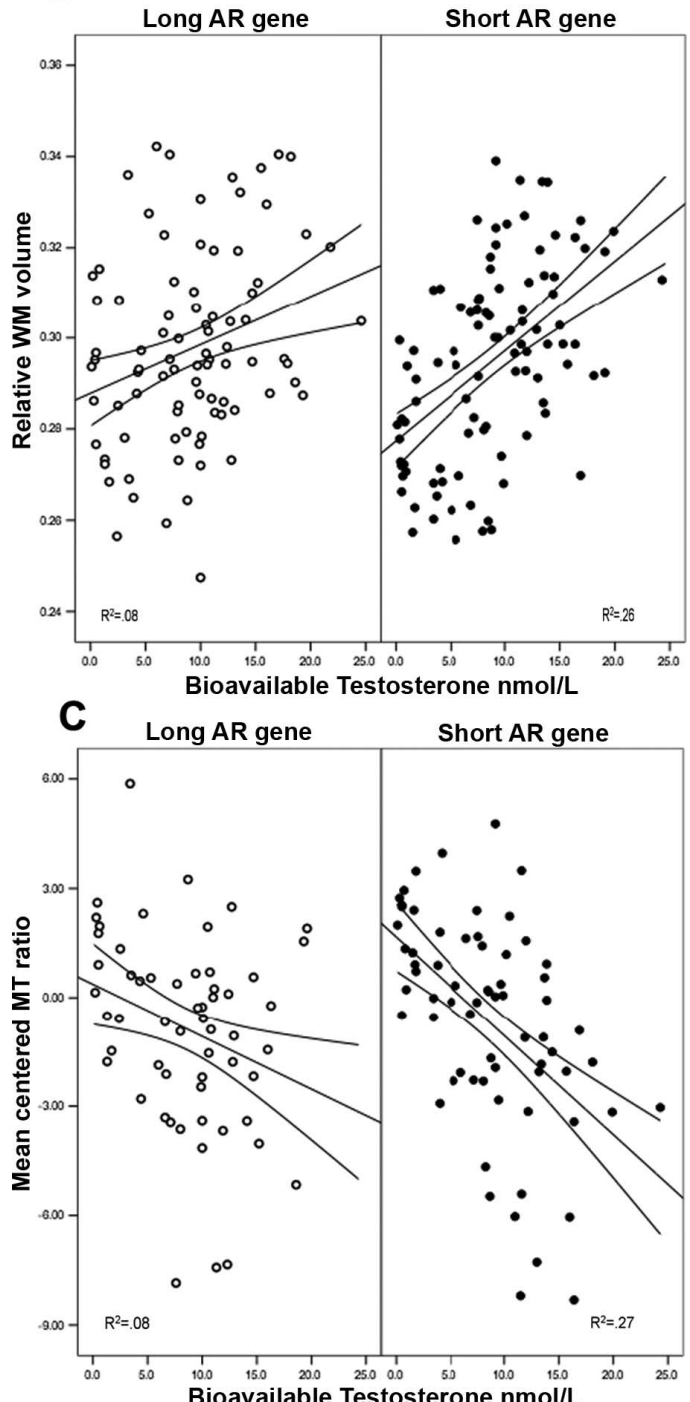

Figure 1. $A$, Relative (brain-volume corrected) volume of WM plotted as a function of age in female (left) and male (right) adolescents. $\boldsymbol{B}$, Relative volume of WM plotted as a function of plasma levels of bioavailable testosterone in male adolescents with low (short AR gene) and high (long AR gene) numbers of CAG repeats in the androgen receptor gene. $C$, Mean-centered values of MTR in white matter plotted as a function of bioavailable testosterone in male adolescents with short and long AR. The WM volumes and MTR values have been summed across all four lobes. 
Table 2. Effect of age on relative volume of WM and mean values of MTR in white matter

\begin{tabular}{|c|c|c|c|c|c|c|}
\hline & \multicolumn{2}{|c|}{ Males } & \multicolumn{2}{|c|}{ Females } & \multicolumn{2}{|c|}{ Sex by age } \\
\hline & $R^{2}$ & $p$ & $R^{2}$ & $p$ & $r_{\mathrm{sp}}{ }^{2}$ & $p$ \\
\hline WM volume & 0.23 & $<0.0001$ & 0.03 & 0.01 & 0.03 & $<0.0001$ \\
\hline MTR & 0.08 & 0.001 & 0.01 & 0.22 & 0.04 & $<0.0001$ \\
\hline
\end{tabular}

$r_{\mathrm{sp}}{ }^{2}$ refers to the squared semipartial correlation coefficient. $p$, Two-tailed test.

Table 3. Relationships between bioavailable testosterone, relative volumes of WM, and mean values of MTR in white matter in male adolescents with short ( $\leq 22$ CAG repeats) and long ( $\geq 23$ CAG repeats) versions of the AR gene

\begin{tabular}{|c|c|c|c|c|c|c|}
\hline & \multicolumn{2}{|c|}{ Short AR gene } & \multicolumn{2}{|c|}{ Long AR gene } & \multicolumn{2}{|c|}{ AR genotype by BioTesto } \\
\hline & $R^{2}$ & $p$ & $R^{2}$ & $p$ & $r_{\mathrm{sp}}{ }^{2}$ & $p$ \\
\hline WM volume & 0.26 & $<0.0001$ & 0.08 & 0.01 & 0.01 & 0.08 \\
\hline MTR & 0.27 & $<0.0001$ & 0.08 & 0.03 & 0.01 & 0.14 \\
\hline
\end{tabular}

$r_{\text {sp }}{ }^{2}$ refers to the squared semipartial correlation coefficient. $p$, Two-tailed test; BioTesto, bioavailable testosterone.

Table 4. Relationships between age and bioavailable testosterone, relative volumes of WM, and mean values of MTR in white matter in male adolescents with short ( $\leq 22$ CAG repeats) and long ( $\geq 23$ CAG repeats) versions of the AR gene

\begin{tabular}{|c|c|c|c|c|c|c|}
\hline & \multicolumn{3}{|c|}{ Short AR gene } & \multicolumn{3}{|c|}{ Long AR gene } \\
\hline & $\overline{R^{2}}$ & Age & BioTesto & $R^{2}$ & Age & BioTesto \\
\hline & & $r_{\mathrm{sp}}^{2}$ & $r_{\mathrm{sp}}^{2}$ & & $r_{\mathrm{sp}}^{2}$ & $r_{\mathrm{sp}}^{2}$ \\
\hline WM volume & 0.32 & $0.06(p=0.006)$ & $0.04(p=0.02)$ & 0.22 & $0.15(p<0.001)$ & $0.00(p=0.89)$ \\
\hline MTR & 0.27 & $0.00(p=0.75)$ & $0.11(p=0.002)$ & 0.08 & $0.00(p=0.64)$ & $0.04(p=0.12)$ \\
\hline
\end{tabular}

$r_{\mathrm{sp}}{ }^{2}$ refers to the squared semipartial correlation coefficient. BioTesto, Bioavailable testosterone.

Table 4 further indicates that the distribution of variance between chronological age and levels of bioavailable testosterone, estimated using semipartial correlations, is different in males with the short and long AR genes, respectively. When considering age and bioavailable testosterone together (i.e., total variance explained; $R^{2}$ ), the amount of variance explained appears slightly higher in males with the short AR gene for both WM volume and MTR. When evaluating the independent contributions of age and bioavailable testosterone using semipartial correlations $\left(r_{\mathrm{sp}}{ }^{2}\right)$, bioavailable testosterone appears to explain significant amount of variance only in males with the short AR gene.

Supplemental Table 1 (available at www.jneurosci.org as supplemental material) provides an overview of the possible relationship between the levels of bioavailable testosterone and the likelihood of psychopathology in the adolescents with short and long versions of the AR gene. Higher levels of bioavailable testosterone were associated with a higher likelihood of depression in male adolescents with the short but not the long AR gene. On the other hand, lower levels of bioavailable testosterone were associated with a higher level of separation anxiety disorder in male adolescents with the long but not the short AR gene. Note that significance levels reported in supplemental Table 1 (available at www.jneurosci.org as supplemental material) are not corrected for multiple comparisons.

\section{Discussion}

First of all, our findings replicate previous studies in observing a striking sexual dimorphism in the WM growth during adolescence. The previous studies suggest that the growth of WM volume in girls is less steep than that of boys, even when a wider range of age is considered (7-19 years) [Lenroot and Giedd (2007), their Fig. 2C], thus arguing against the possibil- ity of missing such a growth "spurt" in our sample caused by a more advanced pubertal development in the female versus male participants. Most importantly, we found that this growth may be driven, at least in part, by testosterone acting via androgen receptors. The moderating influence of AR genotype on the effect of testosterone can be thought of as a case of gene-environment interaction; hormonal environment influences the phenotype more or less depending on a specific variant of the gene. Here, testosterone influenced WM volume to a greater extent in males with the more "efficient" AR (short AR gene), compared with those with a less efficient AR (long AR gene). Furthermore, the observed moderating effect of AR genotype on the relationship between testosterone levels and white matter provides a certain level of causality and specificity not available when simply correlating levels of testosterone with WM volumes. It is important to note that we observed this effect within a normal range of the number of CAG repeats (8-32 repeats in our sample). As pointed out in the Introduction, individuals with 40-66 CAG triplets in the AR gene are known to suffer from Kennedy disease, a neurodegenerative disease characterized by loss of motor neurons in spinal cord and brainstem and accompanied by signs of partial androgen insensitivity (La Spada et al., 1991; Brooks and Fischbeck, 1995).

Our observation of age-related increases in WM volume on the background of decreases in MTR values suggests that testosterone does not act primarily by increasing the rate of myelination during male adolescence. We speculate that testosterone affects axonal caliber, perhaps by influencing the number and/or properties of microtubules and/or neurofilaments (Marszalek et al., 1996; Hoffman et al., 1987). This view is consistent with the pathology of Kennedy disease, as well as with experimental findings of testosterone-induced upregula- 
tion of $\beta$-tubulin expression (Butler et al., 2001; Matsumoto et al., 1993). Future studies in experimental models are necessary to test directly the proposed hypothesis of testosteroneinduced increases in axonal diameter during adolescence. An increased axonal caliber would reduce the number of axons per unit of volume and thus lead to an apparent decrease in the myelination index, as reflected in the lower MTR values. Note, however, that the genotype-based differences in the strength of the relationship between testosterone and MTR were not statistically significant.

Finally, assessment of psychopathology in our normative sample allowed us to ask whether or not there are any possible functional consequences of the age-related increase of WM volume during male adolescence. The DISC Predictive Scales estimate the likelihood of an epidemiological diagnosis of the most common psychiatric disorders. Using this tool, we found that higher levels of bioavailable testosterone were associated with a higher likelihood of depression in male adolescents with the short but not the long AR gene. Previous studies suggest that anabolic androgenic steroids are associated with depression and other side effects (Eklöf et al., 2003; Pope and Katz, 1988). It is possible that the stronger impact of testosterone on the brain of adolescents carrying the short versus long AR gene might have similar, albeit less severe, detrimental effects. Thus, high levels of testosterone in individuals with the more "efficient" AR could represent a male-specific pathophysiological mechanism of depression during adolescence. Although we are unable to make any causal inferences about the relationship between the observed effects of testosterone on white matter and behavior, any variations in the axonal caliber and the related network of microtubules and neurofilaments may affect axonal transport and, in turn, the amount of neurotransmitters, growth factors, and other molecules available at the synapse. The above observations should be treated with caution, however. First, these effects appear subtle and would not survive corrections for multiple comparisons. Second, this report is based on cross-sectional data and, as such, does not allow us to address the dynamics of the possible relationship between changing levels of testosterone during male adolescence and mental health.

In conclusion, our study confirmed sexual dimorphism in the growth of white matter during human adolescence, suggested the role of testosterone and androgen receptors in this growth, and pointed out possible parallels between the effects of testosterone on white matter and on depression during male adolescence. Nonetheless, it should be noted that the interaction between bioavailable testosterone levels and functional polymorphisms in the AR gene explained only a small amount of variance in both the WM volume and MTR values. Clearly, other factors must play a role in mediating age-related changes in white matter during male adolescence. These may include, for example, effects of testosterone metabolites such as dihydrotestosterone and 17- $\beta$-estradiol acting, respectively, via androgen and estrogen receptors (Melcangi et al., 2008), or perhaps involve direct neural effects of gonadotropins, such as luteinizing hormone (Lei and Rao, 2001). Finally, future longitudinal studies will allow investigators to examine, in a more causal manner, whether or not there are any risks associated with fast vs slow growth of white matter during male adolescence vis-à-vis the individual's mental health.

\section{References}

Barry DM, Millecamps S, Julien JP, Garcia ML (2007) New movements in neurofilament transport, turnover and disease. Exp Cell Res 313:2110-2120.

Brooks BP, Fischbeck KH (1995) Spinal and bulbar muscular atrophy: a trinucleotide-repeat expansion neurodegenerative disease. Trends Neurosci 18:459-461.

Butler R, Leigh PN, Gallo JM (2001) Androgen-induced up-regulation of tubulin isoforms in neuroblastoma cells. J Neurochem 78: $854-861$.

De Bellis MD, Keshavan MS, Beers SR, Hall J, Frustaci K, Masalehdan A, Noll J, Boring AM (2001) Sex differences in brain maturation during childhood and adolescence. Cereb Cortex 11:552-557.

Dorn LD, Nottelmann ED, Inoff-Germain G, Susman EJ, Chrousos GP (1990) Perceptions of puberty: adolescent, parent, and health care personnel. Dev Psychol 26:322-329.

Eklöf AC, Thurelius AM, Garle M, Rane A, Sjöqvist F (2003) The antidoping hot-line, a means to capture the abuse of doping agents in the Swedish society and a new service function in clinical pharmacology. Eur J Clin Pharmacol 59:571-577.

Hoffman PN, Cleveland DW, Griffin JW, Landes PW, Cowan NJ, Price DL (1987) Neurofilament gene expression: a major determinant of axonal caliber. Proc Natl Acad Sci U S A 84:3472-3476.

Howell DC (1997) Statistical methods for psychology, Ed 4, p 530. London: Duxbury.

Hsiao PW, Lin DL, Nakao R, Chang C (1999) The linkage of Kennedy's neuron disease to ARA24, the first identified androgen receptor polyglutamine region-associated coactivator. J Biol Chem 274:20229-20234.

Irvine RA, Ma H, Yu MC, Ross RK, Stallcup MR, Coetzee GA (2000) Inhibition of p160-mediated coactivation with increasing androgen receptor polyglutamine length. Hum Mol Genet 9:267-274.

Kucharczyk W, Macdonald PM, Stanisz GJ, Henkelman RM (1994) Relaxivity and magnetization transfer of white matter lipids at MR imaging: importance of cerebrosides and pH. Radiology 192:521-529.

La Spada AR, Wilson EM, Lubahn DB, Harding AE, Fischbeck KH (1991) Androgen receptor gene mutations in X-linked spinal and bulbar muscular atrophy. Nature 352:77-79.

Laule C, Vavasour IM, Kolind SH, Li DK, Traboulsee TL, Moore GR, MacKay AL (2007) Magnetic resonance imaging of myelin. Neurotherapeutics 4:460-484.

Lei ZM, Rao CV (2001) Neural actions of luteinizing hormone and human chorionic gonadotropin. Semin Reprod Med 19:103-109.

Lenroot RK, Gogtay N, Greenstein DK, Wells EM, Wallace GL, Clasen LS, Blumenthal JD, Lerch J, Zijdenbos AP, Evans AC, Thompson PM, Giedd JN (2007) Sexual dimorphism of brain developmental trajectories during childhood and adolescence. Neuroimage 36:1065-1073.

Lucas CP, Zhang H, Fisher PW, Shaffer D, Regier DA, Narrow WE, Bourdon K, Dulcan MK, Canino G, Rubio-Stipec M, Lahey BB, Friman P (2001) The DISC Predictive Scales (DPS): efficiently screening for diagnoses. J Am Acad Child Adolesc Psychiatry 40:443-449.

Marner L, Nyengaard JR, Tang Y, Pakkenberg B (2003) Marked loss of myelinated nerve fibers in the human brain with age. J Comp Neurol 462:144-152.

Marszalek JR, Williamson TL, Lee MK, Xu Z, Hoffman PN, Becher MW, Crawford TO, Cleveland DW (1996) Neurofilament subunit NF-H modulates axonal diameter by selectively slowing neurofilament transport. J Cell Biol 135:711-724.

Matsumoto A, Arai Y, Hyodo S (1993) Androgenic regulation of expression of beta-tubulin messenger ribonucleic acid in motoneurons of the spinal nucleus of the bulbocavernosus. J Neuroendocrinol 5:357-363.

McGowan JC (1999) The physical basis of magnetization transfer imaging. Neurology 53: S3-S7.

Melcangi RC, Garci-Segura LM, Mensah-Nyagan AG (2008) Neuroactive steroids: state of the art and new perspectives. Cell Mol Life Sci 65:777-797.

Paus T (2005) Mapping brain maturation and cognitive development during adolescence. Trends Cogn Sci 9:60-68.

Pausova Z, Paus T, Abrahamowicz M, Almerigi J, Arbour N, Bernard M, 
Gaudet D, Hanzalek P, Hamet P, Evans AC, Kramer M, Laberge L, Leal S, Leonard G, Lerner J, Lerner RM, Mathieu J, Perron M, Pike B, Pitiot A, et al. (2007) Genes, maternal smoking and the offspring brain and body during adolescence: the Saguenay Youth Study. Hum Brain Map 28:502-518.

Peterson AC, Crockett L, Richards M, Boxer A (1988) A self-report measure of pubertal status: reliability, validity, and initial norms. J Youth Adolesc 17:117-133.

Pike GB (1996) Pulsed magnetization transfer contrast in gradient echo imaging: a two-pool analytic description of signal response. Magn Reson Med 36:95-103

Pope HG Jr, Katz DL (1988) Affective and psychotic symptoms associated with anabolic steroid use. Am J Psychiatry 145:487-490.

Rovira A, Grivé E, Pedraza S, Rovira A, Alonso J (2001) Magnetization transfer ratio values and proton MR spectroscopy of normal-appearing cerebral white matter in patients with liver cirrhosis. AJNR Am J Neuroradiol 22:1137-1142.

Schmierer K, Scaravilli F, Altmann DR, Barker GJ, Miller DH (2004) Magnetization transfer ratio and myelin in postmortem multiple sclerosis brain. Ann Neurol 56:407-415.

Schmierer K, Wheeler-Kingshott CA, Tozer DJ, Boulby PA, Parkes HG, Yousry TA, Scaravilli F, Barker GJ, Tofts PS, Miller DH (2008) Quantitative magnetic resonance of postmortem multiple sclerosis brain before and after fixation. Magn Reson Med 59:268-277.

Södergård R, Bäckström T, Shanbhag V, Carstensen H (1982) Calculation of free and bound fractions of testosterone and estradiol-17 beta to human plasma proteins at body temperature. J Steroid Biochem 16:801-810.

Zitzmann M (2007) Mechanisms of disease: pharmacogenetics of testosterone therapy in hypogonadal men. Nat Clin Pract Urol 4:161-166. 